\title{
Digitalization of social infrastructure in small towns of the Middle Urals
}

\author{
Ivan $\mathrm{Kokh}^{*}$ \\ Ural Institute of Management - branch of RANEPA, Ekaterinburg, Russia
}

\begin{abstract}
Social infrastructure of rural areas and cities is of great importance in improving the quality of life of their population. Digital technologies play an ever-increasing role in the development of social infrastructure. Digitalization of social infrastructure in large cities, where there are more favorable conditions for the introduction of Internet technologies due to the availability of reliable networks, unlike other settlements, is of particular importance. The article analyzes the results of sociological research concerning the use of Internet technologies by the population in small towns of the Middle Urals. Special attention is paid to the role of Internet technologies in the transformation of social infrastructure, accessibility of services for residents, especially in small towns.
\end{abstract}

\section{Introduction}

One of the promising directions of socio-economic development of Russia is the digitalization of the economy, the widespread introduction of digital technologies in all spheres of public life. The adopted Project "Digital Economy" provides for accelerated computerization of all the most important sectors of the national economy, as well as housing, household and transport services, education and healthcare and other spheres of life support for the population [6]. Special attention in the Project is paid to measures for digitalization of cities, since they play a crucial role in these processes. It is in innovative cities that a set of technical and organizational measures is being implemented to ensure the highest possible level of quality of services provision and the creation of favorable living conditions for the population.

According to the Project, it is planned to massively introduce cyber-physical systems into urban management, which should ensure high quality of services and involvement of citizens in local government processes, the creation of an environmentally friendly and safe environment, the development of innovative infrastructure, comfortable living conditions. In other words, the task of building and developing "smart" cities in Russia has been set.

There are different approaches to the idea and methods of building smart cities. According to E.V. Pakhomov, "the 3M smart city model of Black \& Veatch is based on the concept of "Measuring", "Moving" data and "Managing" them. This model reflects the fundamental stages of working with urban environment data. The importance of three

*Corresponding author: kia4@mail.ru 
digital technologies required for the implementation of a structure based on information and communication technologies and smart city data is noted: broadband, the Internet of things and big data" [5].

\section{Material and methods}

Digital transformation covers all key sectors of the economy and services, which are concentrated mainly in cities: industrial production, transport and energy, housing and communal services, healthcare and education, trade and services, municipal government systems. This will create conditions for economical solutions to many issues in management, logistics, communications, and increase the attractiveness of the living environment. One of the central places in the creation of "smart cities" belongs to the social infrastructure of the economic sphere and social and consumer services of the population $[8,118]$.

The problems of the place and role of infrastructure in the digitalization of cities are the subject of discussion in many publications. Theoretical problems, issues of development and implementation of the concept of "Smart City" are considered in the article Ablameyko M.S. and Ablameyko S.V. [1, 28-34]. Gorodnova N.V. and Sokolov S.A. consider a smart city as "a unified system of high-tech services using the latest cybernetic methods to improve the infrastructure and economy of urban space" [3, 1441].

In the article by A. A. Burakova and G.A. Bannykh, "smart infrastructure" is considered as "the smooth operation of Internet services for calling and paying for taxis, the ability to monitor road traffic online, an online appointment with a doctor. The official website of the city provides information about the nearest polyclinics in real time, medical care is provided to citizens via the Internet. The official website also contains an information map that clearly shows where you can find the main objects of the city: kindergartens, religious sites, educational institutions" [2,121].

\section{Results and discussions}

The digitalization of cities has caused profound changes in all spheres of public life. The social infrastructure of any municipality is a stable set of material elements (objects of household, communal, medical services, education and cultural institutions, transport and communications, etc.) with which social subjects (residents of a given territory) interact and which create conditions for the rational organization of all the main types of life activities of the population by meeting their needs for various services [4].

The state of the social infrastructure is the most important characteristic of the economic and social development of the municipality, one of the main performance factors of the local administration to meet the needs of the population. The main goal and objective of local authorities in the development of social infrastructure is the creation of comfortable conditions for the local community living. The efficient performance of social infrastructure facilities is considered to be a prerequisite for the social development of the territory.

The sphere of household services remains the weakest component in improving the level and quality of life of the population. Services have comprised and still comprise an extremely small share in consumer spending of the population. In the current conditions, Internet technologies and Internet networks can play a revolutionary role in the development of social infrastructure. With the help of the Internet, goods are purchased, delivery of goods to the appropriate address is made, visits to a doctor are arranged, a wide range of public services is provided. Polyclinics have an opportunity to consult patients on the Internet (WhatsApp, SKYPE; among the first in the Middle Urals is the city of 
Severouralsk), in the future - consultations of specialist doctors, remote treatment of patients, which is especially important for remote settlements and small towns. Internet networks are widely used in the field of education, in particular distant education of schoolchildren and students. Various general education courses for the population, programs of additional education and advanced training are being successfully implemented.

Thus, the priority direction for improving the social infrastructure of settlements is the development of Internet infrastructure, which allows reducing the time spent on household services for city residents, the delivery of products and goods and the provision of a wide range of other services. The introduction of Internet technologies changes the current situation and creates conditions for a more comfortable life. Development of the public service network contributes to the prompt and more complete satisfaction of the needs of the population for obtaining various certificates, paying taxes and other services. The widespread use of the Internet allows for a more rational use of human time and, as a result, creates more comfortable living conditions for the population.

Currently, the Internet is developing rapidly (see diagrams 1,2,3) in small towns of the Middle Urals. Internet infrastructure is a new and modern sphere of employment of the population, which allows improving the quality of life of citizens. The main thing is that the use of Internet infrastructure services provides access to those services that were previously inaccessible to them.

According to the results of our research, it was found that in the city of Severouralsk $(25,157$ people in 2021$)$, the population aged 18 to 45 years regularly uses various services via the Internet (about 50\%). But residents aged 46 to 60 are less likely to use services via the Internet. Many residents over the age of 60 do not use the Internet at all $(41.8 \%)$. Moreover, $23.6 \%$ of the population over the age of 60 and $19.8 \%$ - from 46 to 60 years old regularly use the Internet (see chart 1).

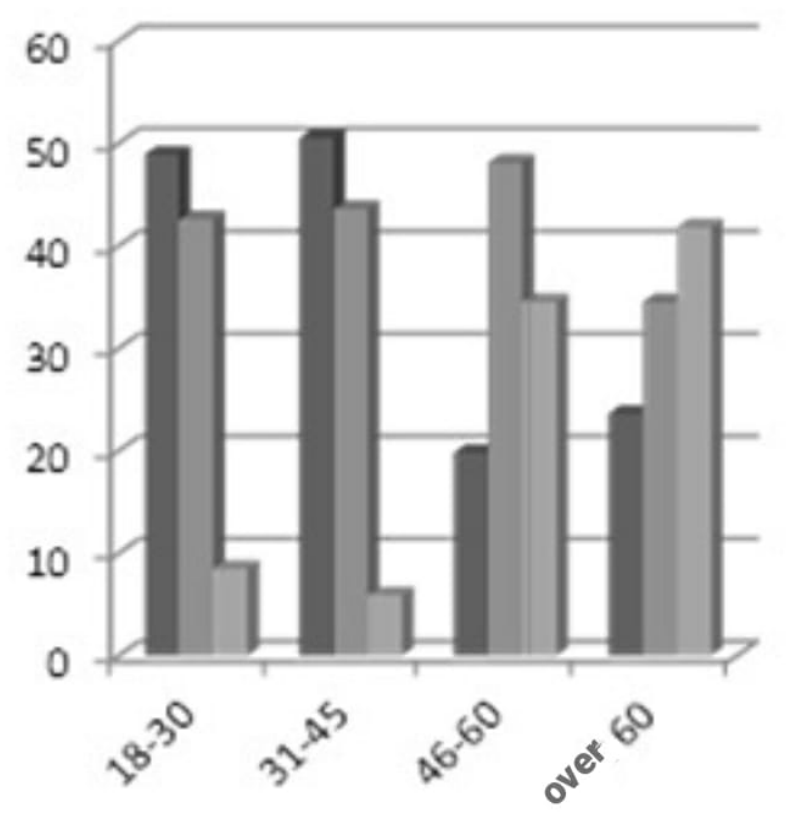

use regularly

use seldom

don't use

Fig. 1. Frequency of using Internet infrastructure services in the city of Severouralsk (as \% to the number of respondents). 
The data from Diagram 2 show that in the city of Zarechny $(65,165$ thousand people 2021 ), the population uses various services via the Internet less often. This is noted by $44 \%$ of the population aged 18 to 30 years, $50 \%$ of the population aged 31 to 46 years, $36 \%$ aged 46 to 60 years and $29 \%$ of people over 60 years. Regular use of social services via the Internet is noted by only $37 \%$ of the young population. But the majority $(63 \%)$ of respondents aged 60 do not use services via the Internet at all. It can be concluded that the population of the city of Zarechny does not use Internet infrastructure services very often. This can also be explained by the fact that the level of development of social infrastructure facilities in this city is higher than in the other two cities studied, as well as proximity to the metropolis: Ekaterinburg is about $40 \mathrm{~km}$ away.

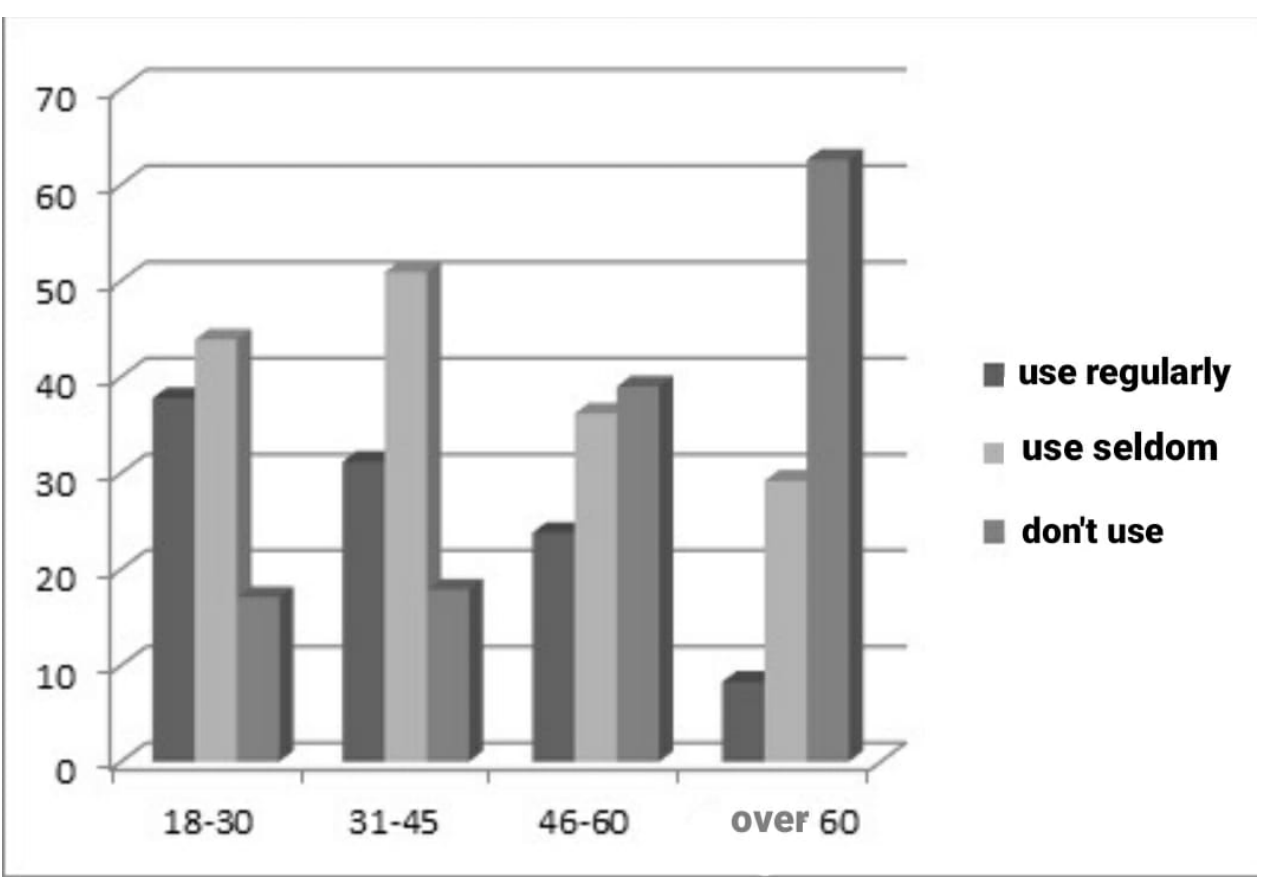

Fig. 2. Frequency of using Internet infrastructure services in the city of Zarechny (as \% to the number of respondents).

Figure 3 shows a very pronounced imbalance between the regular use of services via the Internet and not using services at all. The population aged 18 to 30 years regularly use services and this is noted by $56 \%$ of respondents, $37 \%$ of respondents of this age use it less often and $7 \%$ do not use Internet services at all. The population aged 46 to 60 years rarely use the Internet - 54\%, the population aged 60 years and older - $65 \%$. 


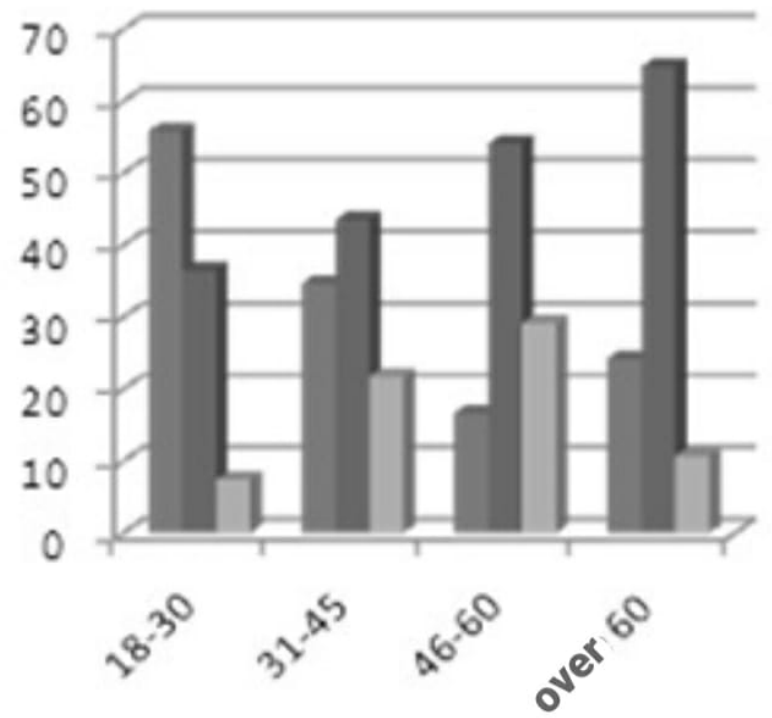

use regularly

use seldom

\section{don't use}

Fig. 3. The frequency of using Internet infrastructure services in the city of Kamyshlov (as \% to the number of respondents).

Let's turn to Table 1, where the services of Internet infrastructure facilities are presented according to the degree of activity of their use.

Table 1. Implementation areas of the Internet infrastructure in small towns.

\begin{tabular}{|c|c|c|c|c|}
\hline \multirow{2}{*}{ № } & \multirow{2}{*}{ Services } & \multicolumn{3}{|c|}{ Answers as \% to the number of respondents } \\
\cline { 3 - 5 } & & Severouralsk & Kamyshlov & Zarechny \\
\hline 1 & In the field of healthcare & 52,0 & 28,8 & 18,1 \\
\hline 2 & Purchase of goods & 35,7 & 34,9 & 39,8 \\
\hline 3 & In education & 35,1 & 31,7 & 16,7 \\
\hline 4 & In housing and communal services & 25,1 & 30,2 & 23,1 \\
\hline 5 & In recreation services & 11,6 & 19,6 & 15,8 \\
\hline 6 & Household services & 8,2 & 9,2 & 9,6 \\
\hline
\end{tabular}

\section{Conclusion}

Healthcare services are the most popular and widespread in Severouralsk $(52 \%$ of respondents), while the population of the other two cities more often buy various goods via the Internet: $39.8 \%$ in Zarechny and $34.9 \%$ of residents of Kamyshlov. Approximately the same proportion of people using the Internet services in the field of housing and communal services from $23 \%$ to $30 \%$. A small number of urban residents resort to household services through the network: from $8 \%$ to $9.5 \%$ of the total number of respondents.

Internet infrastructures are used to solve many tasks, such as automation of management decision-making processes, automation of management activities of the local government administration and social infrastructure institutions, development of long-term forecasts of social processes and development of plans for the strategic development of the municipality. 
Thus, implementation of the "Smart city" concept opens up broad prospects for improving the comfort and quality of life [7, 2-3]. The Internet infrastructure makes it possible to overcome the imbalance in the development of the social infrastructure of the municipality, to create technical conditions for equalizing access to social services not only for residents of small and large cities, but also for the rural population.

\section{References}

1. M. S. Ablameyko, S. V. Ablameyko, Science and Innovation, 6 (184), 28-34 (2018)

2. A. A. Burakova, G. A. Bannykh, Strategies for the development of social communities, institutions and territories: materials of the V International Scientific and Practical Conference, 1, 121 (2019)

3. N. V. Gorodnova, S. A. Sokolov, Economics, Entrepreneurship and Law, 11 (6), 14391456 (2021). Access mode: http://doi.org/10.18334/epp.11.6.112151

4. Infrastructure, Official website Skolkovo (2021). Access mode: http://sk.ru/city/p/engineering_infrastructure.aspx

5. E. V. Pakhomov, Engineering Bulletin of the Don, 4 (2017). Access mode: http://ivdon.ru/ru/magazine/archive/n4y2017/4507

6. The "Smart City" project, The official website of the Smart City project in Russia (2019). Access mode: https://russiasmartcity.ru/about

7. Smart City - concept and technological solutions, Information and analytical bulletin of the RUDN "Future today", 9, 2-3 (2018)

8. V. G. Khalin, Management consulting, 10, 118 (2018) 